Revista Tecnologia e Sociedade, Curitiba, v. 11, n. 23, 2015

ISSN (versão online): 1984-3526

ISSN (versão impressa): 1809-0044

\title{
A hipermodernidade da Buenos Aires fílmica em Medianeras (Gustavo Taretto; 2011)
}

The hypermodernity in the filmic Buenos Aires in the movie Medianeras (Gustavo Taretto; 2011)

\author{
Aline Aparecida de Souza Vaz ${ }^{1}$
}

Artigo submetido em jun./2015 e aceito para publicação em ago./2015.

\section{RESUMO}

O presente trabalho busca reflexões a respeito das experiências estéticas hipermodernas, por meio dos olhares dos personagens, Martin e Mariana, no filme argentino Medianeras - Buenos Aires na Era do Amor Virtual (2011), do diretor Gustavo Taretto. Procura-se analisar como os olhares vagam entre os edifícios da capital argentina fílmica e as representações de mundo através de telas. Percebemos que as experiências estéticas são oprimidas por um efeito mise en abyme, constituído pelo enquadramento da câmera e as janelas da mise en scenè. O flâneur, conceituado por Walter Benjamin, representado no filme em análise, por intermédio dos olhares dos personagens, nesse filme transforma-se em um ciber-flâneur, conceituado por André Lemos, que reconhece uma relação entre o flanar pela cidade e pelo ciberespaço.

Palavras-chave: Estesia. Olhar. Arquitetura. Ciber-flâneur. Hipermodernidade.

\begin{abstract}
This study aims reflections on the aesthetic experiences through the eyes of the characters Martin and Mariana in Argentine film Medianeras (2011), director Gustavo Taretto. Seeks to analyze how the eyes wander among the buildings of the Argentine capital, and representations of the world through screens. We realize that aesthetic experiences are oppressed by a mise en abyme effect created by the camera frame and the windows of the mise en scène. The flâneur, conceptualized by Walter Benjamin, represented in the film in question, through the eyes of the characters, it turns into a cyber flâneur conceptualized by André Lemos, which recognizes a relationship between the city and strolling through cyberspace.
\end{abstract}

Keywords: Esthesis. Look. Architecture. Cyber-flâneur. Hypermodernity.

\section{INTRODUÇÃO}

Gustavo Taretto, nascido em 1965, em Buenos Aires - Argentina - é diretor de filmes que representam a cidade como produtora de vínculos afetivos de seus personagens. O curta-metragem Uma Vez Mais (2010) constitui uma reflexão do tempo-espaço vivenciado por um casal que discute a relação, enquanto caminha pela cidade. Em Hoje Não Estou (2007) a câmera do diretor passeia com o

\footnotetext{
${ }^{1}$ Formada em Letras - Português/Inglês, especialista em Cinema, mestranda em Comunicação e Linguagens, pela Universidade Tuiuti do Paraná e pesquisadora no GP Desdobramentos Simbólicos do Espaço Urbano em Narrativas Audiovisuais. alinevaz88@hotmail.com
} 
Revista Tecnologia e Sociedade, Curitiba, v. 11, n. 23, 2015

ISSN (versão online): 1984-3526

ISSN (versão impressa): 1809-0044

personagem que se adapta a invisibilidade arquitetônica da cidade. Paredes Vizinhas (2005) é o curta-metragem que primeiro enquadra os personagens Martin (Javier Drolas) e Mariana (Mariana Anghileri) na Buenos Aires cinematográfica que virá a ser representada, futuramente, em 2011, no longa-metragem Medianeras.

Em Medianeras - Buenos Aires na Era do Amor Virtual, Gustavo Taretto, suscita a relação entre sujeito - objeto, esse objeto delimitado tanto como o espaço virtual, quanto espaço físico de Buenos Aires, em que os personagens Martin (Javier Drolas) e Mariana (Pilar López de Ayala) transitam entre ser flâneur e transeunte. Percebe-se que ambos os espaços são locais em que o personagem transita, com o cuidado de pertencer não pertencendo, mantendo uma distância pelo olhar mediado por objetos, situação próxima ao que Flusser chama a atenção, quando diz que o sujeito "[...] não sabe mais olhar, a não ser através do aparelho" (FLUSSER, 2011, apud CAETANO, 2012, p. 250).

Sem distinguir o eu das noções de pessoa, personalidade, caráter, indivíduo e individualidade, Claudine Haroche (2008) trata da existência de um desengajamento, ou seja, um descompromisso que resulta das sensações contínuas exercidas sobre o eu, o que influencia diretamente as relações entre sensação, percepção, consciência, reflexão e sentimentos.

Em uma sociedade em que se rompem as fronteiras entre objetos materiais reais e imagens virtuais, Haroche pressupõe:

Sob o impacto da globalização, as sociedades contemporâneas tendem a se tornar sociedades que se transformam de maneira contínua; sociedades flexíveis, sem fronteiras e sem limites; sociedades fluidas, líquidas. Tais condições têm consequências sobre os traços de personalidade, dos mais contingentes e superficiais aos mais profundos, sobre os tipos de personalidade que tendem a desenvolver, e mesmo encorajar, e também sobre a natureza das relações entre os indivíduos. (HAROCHE, 2008, p.123).

Sobre o sujeito hipermoderno, Haroche questiona a capacidade contemporânea de sentir, confundida com o fluxo de sensações e ressalta, "teria se estabelecido uma modificação na maneira de experimentar e exprimir os sentimentos em relação aos outros e a si mesmo?" (HAROCHE, 2008, p. 134).

Desse modo, por meio da análise do filme Medianeras - Buenos Aires na Era do Amor Virtual, em que há uma busca pela mediação do olhar decodificado por símbolos imagéticos, o artigo procura refletir à luz da possibilidade da experiência do sujeito hipermoderno perceber o mundo por janelas que enquadram possíveis 
Revista Tecnologia e Sociedade, Curitiba, v. 11, n. 23, 2015

ISSN (versão online): 1984-3526

ISSN (versão impressa): 1809-0044

olhares dos personagens representados. Assim, a análise fílmica argumenta sobre o que é visto na tela do cinema, relacionando-se com teóricos que podem tornar as interpretações verificáveis em torno dos olhares possíveis de serem comparados com o mundo dito real.

\section{O MODO DE HABITAR REPRESENTADO NA ARQUITETURA FÍLMICA}

O filme Medianeras - Buenos Aires na Era do Amor Virtual inicia com uma descrição imagética e voz off do personagem Martin, como forma de apresentação e decodificação da capital argentina, uma representação de mundo, por meio da janela do cinema que apresenta um sintoma da dita realidade apreendida pelos sujeitos que a habitam:

Buenos Aires cresce descontrolada e imperfeita. É uma cidade superpovoada num país deserto. Uma cidade onde se erguem milhares e milhares de prédios sem nenhum critério. Ao lado de um muito alto, tem um muito baixo. Ao lado de um racionalista um irracional. Ao lado de um estilo francês, tem um sem estilo. Provavelmente essas irregularidades nos refletem perfeitamente. Irregularidades estéticas e éticas. Esses prédios que se sucedem sem lógica demonstram total falta de planejamento. Exatamente assim é a nossa vida, que construímos sem saber como queremos que fique. Vivemos como quem está de passagem por Buenos Aires. Somos criadores da cultura do inquilino. Prédios menores para dar lugar a outros prédios, ainda menores. Os apartamentos se medem por cômodos, vão daqueles excepcionais, com sacadas, sala de recreação, quarto de empregada e depósito, até a quitinete, ou "caixa de sapato". Os prédios, como muita coisa pensada pelos homens, servem para diferenciar uns aos outros. Existe a frente e existe o fundo. Andares altos e baixos. Os privilegiados são identificados pela letra $A$, às vezes $B$. Quanto mais à frente no alfabeto, pior o apartamento. Vista e claridade são promessas que poucas vezes se concretizam. O que esperar de uma cidade que dá as costas ao mar? É certeza que as separações e os divórcios, a violência familiar o excesso de canais a cabo, a falta de comunicação, a falta de desejo, a apatia, a depressão, os suicídios, as neuroses, ataque de pânico, a obesidade, a tensão muscular, a insegurança, a hipocondria, o estresse, o sedentarismo, são culpa dos arquitetos e incorporações. Esses males, exceto o suicídio, todos me acometem (MEDIANERAS; 2011).

Pelo viés do personagem Martin remete-se ao pensamento de Heidegger que observa o espaço da habitação como um modo de o homem ser e estar no mundo, em que "ser" "se deriva de sedere, estar sentado. Nós falamos de "residência". Assim se denomina o lugar onde se demora o habitar. Demorar-se é estar presente junto a..." (HEIDEGGER, 1979, p. 450). No filme em análise, percebe-se uma necessidade de refletir a respeito do ser e estar no mundo, pois o pertencer constitui um ser e pensar, que constrói formas de identidades. Heidegger discorre sobre uma subjetividade afetada pela sensibilidade, em que pensar significa multiplicidades de 
Revista Tecnologia e Sociedade, Curitiba, v. 11, n. 23, 2015

ISSN (versão online): 1984-3526

ISSN (versão impressa): 1809-0044

representações em "conhecer o mundo" e "possuir o mundo". "O conceito de mundo está como que entre a "possibilidade da experiência" e o "ideal transcendental" e significa assim, em seu núcleo, a totalidade da finitude do ser humano." (HEIDEGGER, 1979, p. 311).

Também é possível analisar a fala do personagem fílmico à moda de Bachelard (1978) em "A poética do Espaço", em que a casa abriga o devaneio, protege o sonhador e o permite sonhar em paz. O protagonista, Martin, ao suscitar que a cidade cresce descontrolada, imperfeita e irregular, culpa os males da sociedade como reflexo de um mal arquitetônico, que abriga e separa a sociedade, desconstruindo o espaço que deveria proteger e alimentar os sonhos, negando então os conceitos de habitar e de morar nos termos de Heidegger e Bachelard.

Não há saída, o homem que limpa os vidros, amarrado em uma corda bamba é refém de uma arquitetura que transmite insegurança. Os prédios que observamos têm muitos espelhos, que se caracterizam por não deixar rastros (o homem limpa os vidros), e ao dar as costas ao mar, refletem apenas a própria arquitetura, janelas distorcidas dentro de janelas, que oprimem o sujeito - personagem em um efeito mise en abyme (Figura 1).

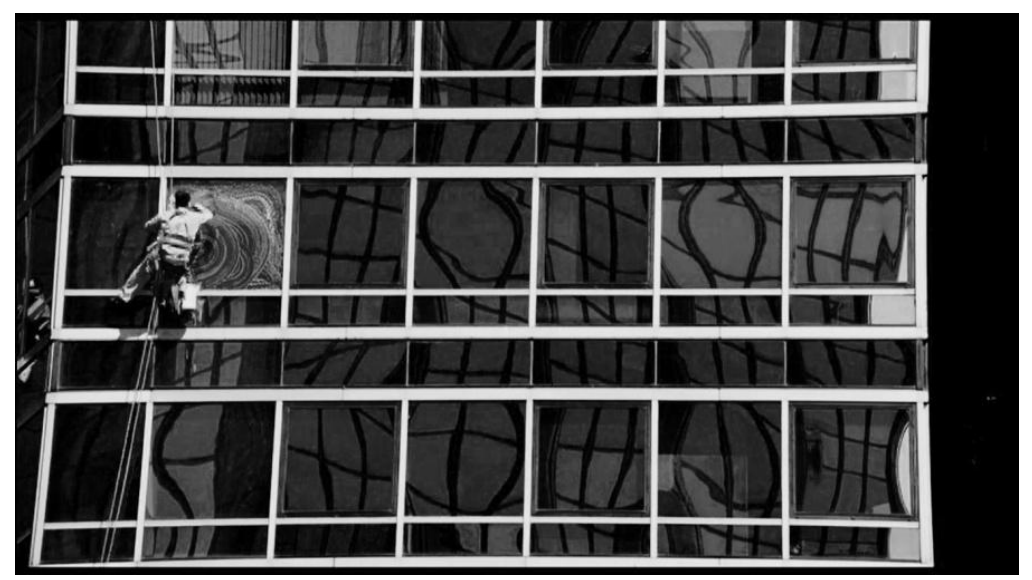

Figura 1: Frame do filme Medianeras: Mise en abyme - reprodutividade sem fim - conceito definido por André Gide, em 1893.

Podemos pressupor que a cena descrita transpõe para a tela a imagem de uma cidade que olha e é olhada para o protagonista, que é afetado "através" de uma arquitetura que o norteia. Nesse caso, o uso da palavra "através" não é ocasional, já que o olhar "atravessa" o indivíduo que habita essa cidade, reflete nas moradias irregulares a irregularidade de personagens que pertencem não pertencendo, conhecem o mundo, mas talvez não o possuam. Ao passo que os edifícios diferenciam os sujeitos pelo poder de aquisição, abrigam e sufocam moradores 
Revista Tecnologia e Sociedade, Curitiba, v. 11, n. 23, 2015

ISSN (versão online): 1984-3526

ISSN (versão impressa): 1809-0044

presos em casas que não constituem subjetividade, distanciam as possibilidades sensíveis, destinados a um comportamento de isolamento, refletindo um comportamento coletivo, Clarissa Ribeiro (2004) observa no artigo "Do flâneur ao ciborg - teorias filosóficas do espaço", que os edifícios se realizam em função de um propósito comum, observados como uma representação física de um sintoma de comportamento de grupo, representando uma sociedade e seus modos de vivenciar a cidade.

O personagem diz: "Os privilegiados são identificados pela letra $A$, às vezes B. Quanto mais à frente no alfabeto, pior o apartamento." Marc Augé (2007), em "Não Lugares - introdução a uma antropologia da supermodernidade", observa que os espaços de não-lugares identificam seus usuários por números. Os moradores da Buenos Aires, enquadrada por Gustavo Taretto, são identificados por letras, o que constitui uma relação de solidão e similitude com o espaço fílmico. Medianeras: Buenos Aires na Era do Amor Virtual, por intermédio do olhar do diretor, sugere que a moradia suscitada por Bachelard (2000) estaria transformando-se em um nãolugar, como os espaços de passagens: aeroportos, supermercados e hotéis, apontados por Augé, lugares em que não se demora, logo não se habita.

\section{O OLHAR FÍLMICO: ENQUADRAMENTOS POSSÍVEIS}

Para que o sujeito habite o mundo, compreenda e o possua, é preciso olhar e ser olhado para e pelo mundo. Para que se constitua uma experiência estética, DidiHuberman (2010), suscita a experiência de ser olhante e olhado. Os nomes Martin e Mariana iniciam com a palavra "mar", Buenos Aires que dá as costas para o mar, dá as costas para os seus personagens?

A relação do olhar, sujeito-cidade, é invocada no relato do personagem Martin:

Para a psiquiatria sou um fóbico em recuperação. Após repetidos ataques de pânico, eu me fechei em casa. Por uns dois anos, não saí. [...] Fiquei totalmente isolado com medo. Com a estratégia do psiquiatra fui perdendo o medo da cidade, do mundo lá fora, dos outros. Tirar fotos. Um jeito de redescobrir a cidade e as pessoas. Procurar a beleza, mesmo onde ela não existe. Observar é estar e não estar. Ou talvez estar de um jeito diferente. Assim, distraidamente, fui me afastando. Não ando de ônibus, nem de taxi, muito menos de metrô. Avião então, nem pensar, só me desloco a pé. Só preciso dos pés e da mochila que levo para todo lado. Conteúdo: Uma câmera Leica D-Lux 3 de 10 megapixels, Rivotril em gotas a 0,25\%, Amoxilina 500, Ibuprofeno, óculos de sol, uma capa plástica, um Victorinox 
Revista Tecnologia e Sociedade, Curitiba, v. 11, n. 23, 2015

ISSN (versão online): 1984-3526

ISSN (versão impressa): 1809-0044

de 21 funções, lanterna, pilhas, preservativos, três unidades, 400 pesos em notas miúdas, um ipod de 60Gb. Tenho mais de 8.000 músicas. Três filmes de Tati, um caderno e uma folha plastificada com instruções com o que fazer em caso de acidente ou ataque de pânico (MEDIANERAS; 2011).

O protagonista relata uma atitude que dialoga com o personagem conceitual citado por Walter Benjamin (1989), o flâneur, um "ser ótico" por excelência. Benjamin também ressalta a representação das cenas construídas por imagens do cotidiano, que se tornam simulacros da própria vida. No caso de Martin, o torna observador, o coloca próximo da multidão, mas protegido por um olhar mediado pela câmera fotográfica.

\begin{abstract}
Cada um de nós pode observar que uma imagem, uma escultura e principalmente um edifício são mais facilmente visíveis na fotografia que na realidade. A tentação é grande de atribuir a responsabilidade por esse fenômeno à decadência do gosto artístico ou ao fracasso dos nossos contemporâneos. Porém somos forçados a reconhecer que a concepção de grandes obras modificou simultaneamente com o aperfeiçoamento das técnicas de reprodução. Não podemos agora vê-las como criações individuais; elas se transformaram em criações coletivas tão possantes que precisamos diminuí-las para que nos apoderemos delas. (BENJAMIN, 1994, p.104).
\end{abstract}

Para que Martin possa apoderar-se de uma arquitetura que se apodera é preciso diminuí-la pela janela da câmera fotográfica, enquadrando a cidade é possível escolher o que é olhado e olhante, é possível vivenciar uma reprodução de uma dita realidade emoldurada, o olhar cinematográfico é selecionado.

Em uma das fotografias de Martin (Figura 2) percebemos que a janela da lente da câmera registra uma janela de vidro, que enquadra o sujeito, deformado por gotas da chuva. O efeito mise en abyme, é recorrente no mundo olhado por janelas, que muitas vezes pode deformar o olhar. "O poeta, como tantos outros, sonha atrás da vidraça. Mas, no próprio vidro, descobre uma pequena deformação que vai propagar a deformação do universo" (BACHELARD, 1978, p. 299). 
Revista Tecnologia e Sociedade, Curitiba, v. 11, n. 23, 2015

ISSN (versão online): 1984-3526

ISSN (versão impressa): 1809-0044

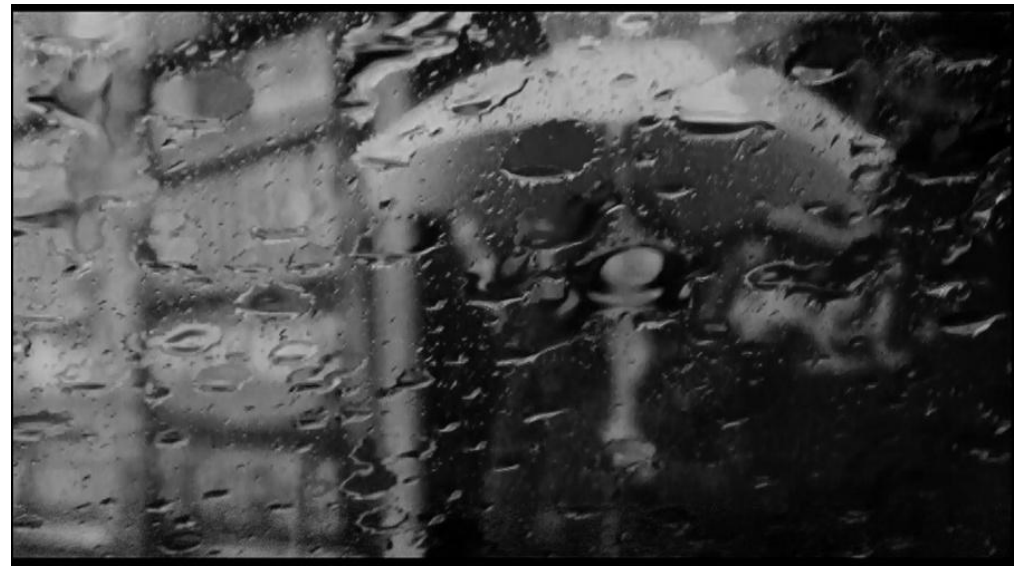

Figura 2: Frame do filme Medianeras - $\mathrm{O}$ olhar mediado pelo aparelho.

Mariana, personagem da obra analisada, confirma as características do flâneur ao folhear o popular livro "Onde Está Wally?":

\begin{abstract}
Tenho esse livro desde os 14 anos e é, que me perdoem os grandes escritores, o livro da minha vida. É a origem da minha fobia de multidões e criou em mim uma angústia existencial bem particular. Ele representa de um jeito dramático a angústia de saber que sou alguém perdido entre milhões. Os anos passaram e ficou uma página sem resolver. Wally na cidade. Eu o encontrei no shopping, no aeroporto e na praia, mas na cidade não o encontro. Sei que o nervosismo cega, mas não consigo achar. Então me pergunto: se mesmo sabendo quem eu procuro não consigo achar, como vou achar quem eu procuro se nem sei como é? (MEDIANERAS; 2011).
\end{abstract}

Wally é o transeunte que se enfia na multidão, aquele que Martin procura tornar-se com a ajuda da terapia, a câmera e sua mochila, que é abastecida como alguém que prepara um kit de sobrevivência, prestes a adentrar em uma selva. $A$ cidade ganha um caráter de floresta de signos, que Martin tenta decodificar por meio da observação mediada pela câmera. Mariana não quer pertencer à cidade, ela quer encontrar alguém que não sabe como é, mas que está perdido na multidão. $O$ nervosismo de pertencer não pertencendo a essa multidão cega as possibilidades de encontro com alguém que também vive a angústia e anulação coletiva. Os personagens não se olham.

Olhar para a cidade causa pânico em Martin, angústia em Mariana. Olhar para a cidade que os priva de claridade e vista, que os prende em pequenos apartamentos com pouca luminosidade, em que janelas ilegais aparecem como rotas de fuga, para encontrar um pouco de luz, mas que são medianeras tomadas por anúncios publicitários, constitui em um olhar para soluções provisórias e anúncios que indicam quantos minutos separam as janelas de não-lugares, como os supermercados e lanchonetes (Figura 3). 


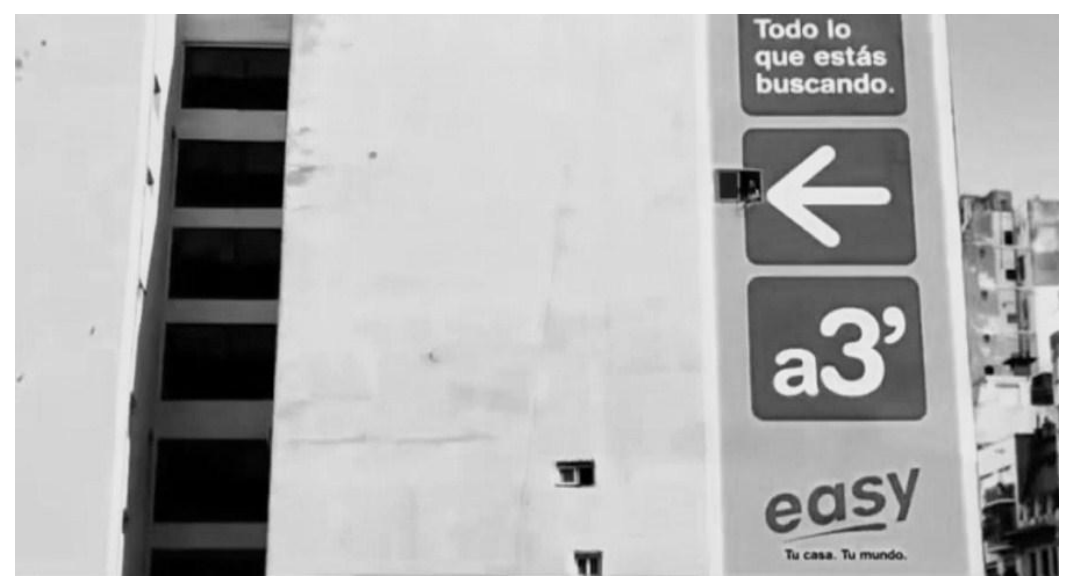

Figura 3: Frame do filme Medianeras:

As medianeras representam rotas de fuga, mas que frustram os olhares.

Diante de um olhar oprimido, dentro de suas casas, os moradores da Buenos Aires de Taretto, acabam por encontrar a luz que procuram na tela do computador. "Como podemos ter deixado de acreditar em nossos próprios olhos para crer tão facilmente nos vetores da representação eletrônica e, sobretudo, no vetor velocidade da luz?" (VIRILIO, 1993, p.31).

As janelas para o mundo de Martin e Mariana transformam-se em telas, transformando as experiências sensíveis dos personagens que olham para o mundo representado e não mais o mundo vivido, observa-se uma "desintegração do nosso mundo em um aglomerado de grupos de interesse privado, material e espiritual, vivendo em mônadas sem janelas, ainda mais isolados do que precisamos ser" (BERMAN, 1990, p.31-2).

Para Haroche (2008), o sujeito hipermoderno experimenta a necessidade da presença do outro, afastado dele, uma presença abstrata, inconsistente, permutável e até inexistente. Martin afirma: "Há mais de dez anos, sentei em frente ao computador e tenho a sensação que nunca mais levantei". O olhar para o mundo teria transformado o flâneur em um observador que vaga no ciberespaço?

\section{O FLÂNEUR HIPERMODERNO}

Partindo do conceito de hipermodernidade, percebe-se 0 sujeito hipermoderno inserido numa liquidez, em relação à qual Bauman (1993) preocupase com a qualidade das interações imediatas, fluidas. Fromm (apud HAROCHE, 
Revista Tecnologia e Sociedade, Curitiba, v. 11, n. 23, 2015

ISSN (versão online): 1984-3526

ISSN (versão impressa): 1809-0044

2008, p.126) enfatiza que o ao se libertar dos vínculos pessoais tradicionais de indivíduo a indivíduo, a emancipação afeta a estrutura de caráter. Haroche conclui:

Desse modo, ele torna visíveis os processos que levam ao isolamento e à impotência do indivíduo, à falta de proteção das novas condições que provocam efeitos psicológicos maiores: a liberdade do indivíduo faz nascer a dúvida, a incerteza e um sentimento de impotência e de insegurança, outra maneira de dizer que essa autonomia acompanha a emergência de um sentimento complexo e que é fonte de angústia, o sentimento do eu, o medo de perdê-lo. (HAROCHE, 2008, p.126)

Mariana reclama que o olhar vendado por prédios e fios escondem o mar e o céu, o que resulta em uma relação virtual com o mundo, uma escapatória, a tela como um novo olhar para o mundo, uma solidão coletiva. Lemos (2001) pressupõe uma modificação do sujeito que vaga em estado de abandono a observar as multidões, o flâneur agora é um ciber-flâneur:

\begin{abstract}
Vivemos hoje uma relação cada vez mais simbiótica entre o espaço da cidade e o novo espaço cibernético, o ciberespaço. Nesta analogia, podemos ver a navegação hipertextual pela Internet como o exercício de um ciber-flâneur e seu passeio pelo mar de dados. Não mais apenas sobre espaços físicos, mas sobre as malhas virtuais do ciberespaço. Em ambos os processos está em jogo um arranjo do espaço (físico ou cibernético) através de um modelo de conexão generalizada, descentralizada, cujo ponto de partida é constantemente deslocado através da atividade da errância. Não podemos prever que caminho o internauta vai tomar com os links propostos. Neste sentido, flanar numa cidade ou navegar por hipertextos evoca um mesmo processo: leitura (relação corpo -texto) e mapeamentos (relação corpo - espaço), fundindo as figuras do leitor (que segue o mapa) e do escritor (que faz o mapa), do conformista que segue e do aventureiro que faz. (LEMOS, 2001, p.02).
\end{abstract}

Martin incorpora a rotina do ciber-flâneur: "A internet me aproximou do mundo, mas me distanciou da vida. Faço coisas de banco e leio revistas pela internet, baixo música, ouço rádio pela internet, compro comida pela internet, converso pela internet, estudo pela internet, jogo pela internet, faço sexo pela internet e procuro passeador de cachorro."

O personagem também determina seus encontros românticos observando candidatas no ciberespaço: "Concluí que esses encontros são como combos do McDonald's. Nas fotos, é tudo melhor, maior e mais apetitoso. Cada vez que vou a um encontro tenho a mesma decepção que vem diante de um Big Mac". Procurar alguém para sair é como procurar uma refeição no cardápio, percebemos que as características pessoais da pessoa escolhida são organizadas por ícones (Figura 4). É a organização das imagens que irá determinar algum interesse em Martin ou não. É como montar um sanduíche, qual a sua combinação preferida? 
Revista Tecnologia e Sociedade, Curitiba, v. 11, n. 23, 2015

ISSN (versão online): 1984-3526

ISSN (versão impressa): 1809-0044

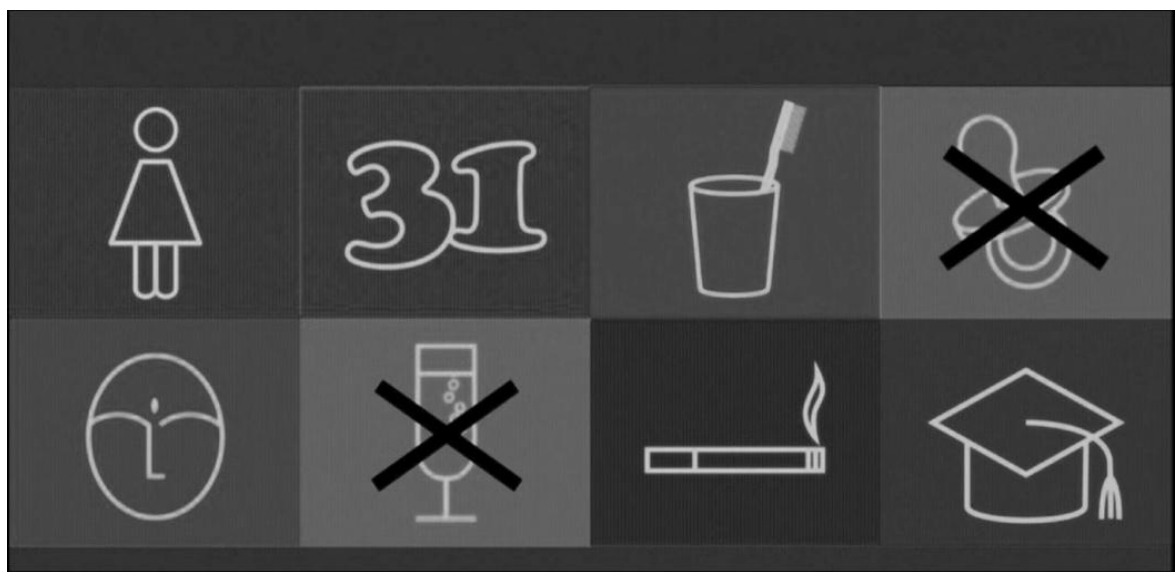

Figura 4: Frame do filme Medianeras:

Ícones que caracterizam o sujeito no ciberespaço.

O mundo constituído pelo uso de códigos comunicacionais, segundo Bally (1951), aceita a linguagem como expressão de pensamentos e acrescenta que como sistema de pensamento, a linguagem deforma-se pela subjetividade. Sendo assim, ela não reflete e sim refrata a realidade e opera uma modificação dos fenômenos. A subjetividade é a parte afetiva que nos constitui. Emoções, impulsos e desejos são expressos na linguagem. Ao considerar uma linguagem afetiva, não se exclui a condição social do interlocutor, pois ela transita de um estado psicológico para o social.

A linguagem - representação de mundo - do flâneur representado por Martin é alterada pelos hipertextos. Novas formas de comunicação que se deslocam do espaço físico para o ciberespaço constroem um novo olhar decodificante e novas experiências estéticas. Martin, o flâneur, não precisa mais se deslocar até a rua para desempenhar a função de observador, o mundo está representado dentro da sua casa, o olhar é iluminado pela luz que o imobiliza em uma relação com o simulacro. O novo acesso ao mundo que surge como uma estesia passa por uma automatização: "Todo impulso em direção à estesia está ameaçado de uma recaída na anestesia" (GREIMAS, 2002, p.80).

O personagem que vê o ciberespaço como uma possível aproximação do mundo, torna-se refém de uma mise en abyme, aprisiona-se na cidade, que o aprisiona na casa, que o aprisiona na tela do computador, que por sua vez o aprisionará em sites de relacionamentos e hiperlinks.

Kati Caetano (2012, p. 256) compreende que o sujeito imergido no ciberespaço "é tomado pela impressão de presença no mundo e proximidade com 
Revista Tecnologia e Sociedade, Curitiba, v. 11, n. 23, 2015

ISSN (versão online): 1984-3526

ISSN (versão impressa): 1809-0044

as pessoas e coisas, ao mesmo passo que se posiciona numa atitude de imobilidade física e descorporificação com respeito àquilo que se processa aquém da tela do computador". Nesse sentido, pode-se dizer que Martin, agora um ciber-flâneur, encontra-se anestesiado pela automatização. Mariana diz que "o futuro está na fibra ótica, ninguém vai esperar você com a casa quentinha". Na tentativa de não anularse na multidão, o sujeito - personagem fílmico anula-se na tentativa solitária de experimentar uma representação de mundo, o que Berman (1990, p. 33) indicou como um sonho de liberdade que aprisiona.

Conhecemos os riscos indicados pelo filme de Gustavo Taretto. Na janela do ciberespaço, os personagens tornam-se simulacros de si mesmos, reféns do comodismo, da proteção que a tela impõe, acostumados com o estar nem dentro e nem fora, interagindo com as imagens do mundo.

\section{A DESCONSTRUÇÃO DO SIMULACRO: ACONTECIMENTO-APROPRIAÇÃO}

Heidegger (1979) chama a atenção para a relação homem e máquina, em que se desconstrói uma representação técnica, apenas tecnicamente, pois é preciso refletir sobre o ponto de vista do ser. A reprodutibilidade técnica torna-se apropriação de uma linguagem, própria de conhecimento e apropriação de mundo, que Heidegger trata como acontecimento-apropriação, entregue à linguagem como propriedade. Apropriar-se e tornar-se para si, constitui uma identidade, ser e estar de modo a interagir com as apresentações e representações que afetam o sujeito mediado pelo olhar, que o coloca no mundo e o torna parte dele.

A reprodutibilidade técnica pode constituir os simulacros, indicados por Arlindo Machado (1984), como significadores das coisas que representam. "O signo existe, grosso modo, para remeter para alguma coisa fora dele mesmo, ou seja, para "representar" algo que não é ele próprio, daí a definição clássica de signo: aquilo que está no lugar de alguma coisa" (MACHADO, 1984, p. 20). Todos esses simulacros que representam o mundo, também podem distanciar o sujeito do mundo, que protegido de uma dita realidade, reproduz uma solitária dita realidade constituída pelo olhar mediado pela proteção do anonimato.

Em Medianeras - Buenos Aires na Era do Amor Virtual há a representação do simulacro, a relação de mundo que Martin constrói mediada por aparelhos, as vitrines decoradas por Mariana, a cena que sugere uma relação erótica entre 
Revista Tecnologia e Sociedade, Curitiba, v. 11, n. 23, 2015

ISSN (versão online): 1984-3526

ISSN (versão impressa): 1809-0044

Mariana e seu manequim, evidenciam uma relação com 0 mundo das representações.

No filme em análise, a apropriação do simulacro, evidenciada por Heidegger se dá pelo movimento do olhar entre vigilante e vigiado:

\begin{abstract}
O sentido de vigiar, atualizável em algumas ocorrências do vocábulo "olhar", é sintomático de uma sociedade de relações verticalizadas, que se manifestam, inclusive, nos regimes de visibilidade presentes nos encontros intersubjetivos, sejam eles entre pessoas e entre pessoas e coisas. Quem vigia determina uma posição de privilégio, não de classe ou grupo, mas de competências e saberes. $\mathrm{O}$ alcance de sua mirada, mesmo que enquadrado pelos limites de um aparato ou espaço, avoluma-se porque circunscrito a um contexto de predefinições e potencialidades: de aproximação, retenção, ampliação, recuo, comparações. É visto, além disso, no bojo de uma conjuntura em que as ações e os sujeitos estão determinados por certas pretensas normalidades. (CAETANO; FISCHER, 2014, p. 02).
\end{abstract}

A obra cinematográfica em análise constrói personagens conscientes do olhar que os coloca em uma situação de estar sem ser (multidão). Martin que passa por um processo de inserção na cidade, por meio da fotografia e caminhadas, na cena final ganha a personificação de Wally. No momento em que Martin pertence à multidão, Mariana desempenha o olhar de flâneur, que finalmente encontra o Wally na cidade. Em um jogo de câmera, o olhar de Mariana desconstrói uma mediação do olhar, agora não há mais a tela do computador, nem as vitrines, ela corre para a rua, derruba um manequim como sinal de ruptura do simulacro e enfim se vê inserida na multidão, olhando e sendo olhada. A câmera se distancia dos personagens que se tornam transeuntes - a experiência do espectador é de flanar Martin e Mariana, agora multidão (Figura 5). 
Revista Tecnologia e Sociedade, Curitiba, v. 11, n. 23, 2015

ISSN (versão online): 1984-3526

ISSN (versão impressa): 1809-0044

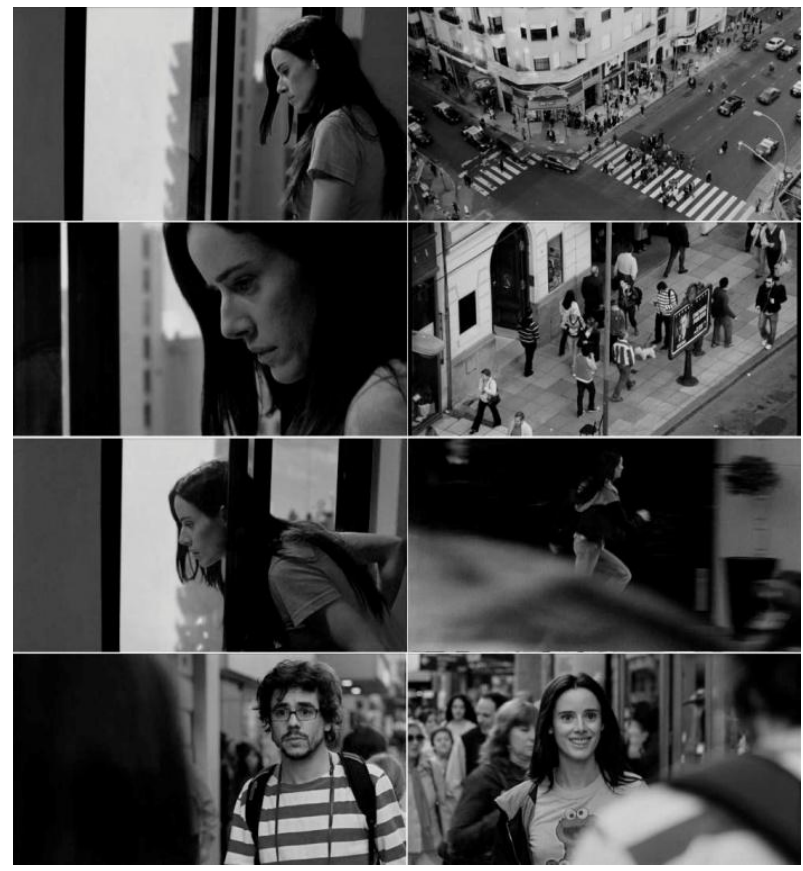

Figura 5: Frame do filme Medianeras:

Movimento olhante e olhado - Flâneur e Transeunte.

Caetano e Fischer também analisam a posição daquele que é observado:

[...] o vigiado está naturalmente apequenado, não como classe ou grupo, mas como aquele que, incapaz de assumir-se sujeito do discurso, torna-se a terceira pessoa, de quem se fala, a quem se vê, destituído de sua possibilidade de interlocução, interação, defesa. Os olhares assim divergidos não configuram meros desencontros; instituem espacialidades pertinentes do ponto de vista comunicacional entre interior/exterior, visibilidade/invisibilidade; mediações/imediações e estados modo passionais intensos, entre atos mecanizados e livres. (CAETANO; FISCHER, 2014, p. 02).

$\mathrm{Na}$ cena descrita percebemos um movimento de vigilância para vigiado. Martin que até aquele momento do filme coloca-se como um observador mediado por aparelhos - telas -, torna-se vigiado por Mariana, que logo se torna vigiada pela câmera que se distancia do casal que se olha, apequenando os personagens e proporcionando uma visibilidade aos nossos olhos daqueles que se tornam vigiados em meio à multidão, que naquele momento pertencem, estão no mundo e apropriam-se dele.

\section{CONSIDERAÇÕES FINAIS}

Ao analisar as percepções de mundo dos personagens Martin e Mariana, no filme Medianeras - Buenos Aires na Era do Amor Virtual, compreende-se um processo comunicacional dos personagens, construção de linguagem - mundo - 
Revista Tecnologia e Sociedade, Curitiba, v. 11, n. 23, 2015

ISSN (versão online): 1984-3526

ISSN (versão impressa): 1809-0044

entre o olhar do flâneur e as mediações, que representam um mundo afetado pelos simulacros de uma dita realidade. Assim, na correlação entre as imagens fílmicas e as teorias aplicadas, sugere-se uma aproximação entre as vivências experimentadas pelos personagens e as experiências do mundo dito real.

O espaço fílmico que representa um olhar mediado pelas escolhas de enquadramentos determinados pelo diretor, Gustavo Taretto, constitui olhares enquadrados por janelas que criam um efeito mise en abyme. O espectador mediado pelo olhar da câmera, olha e é olhado pela cidade cinematográfica que nas janelas da mise en scenè enquadram os olhares dos personagens. Janelas do mundo dito real, do mundo dito digital e do mundo dito fílmico, constituem personagens que se apropriam de um mundo representado pelo que enquadra e pelo que é enquadrado.

Acompanhando o pensamento de André Lemos (2007, p. 139) ao sugerir que as modificações nas práticas comunicacionais afetam o interior dos espaços físicos, "reconfigurando a arquitetura externa e interna das cidades", a Buenos Aires fílmica revela-se reconfigurada pelo modo dos personagens habitarem a arquitetura, como ela é ressignificada pelas janelas e olhares.

Entre o flanar pela cidade e a janela do ambiente digital o olhar é resignificado pela técnica decodificante da linguagem que se constitui pela percepção e representação do mundo do diretor argentino, na tela do cinema, em Medianeras: Buenos Aires na Era do Amor Virtual.

\section{REFERÊNCIAS}

AUGÉ, Marc. Não-Iugares. Papirus Editora, 2007.

BALLY, Charles. Traite de stylistique francaise. 3e ed., nouveau tirage. Georg, 1951.

BACHELARD, Gaston. Os pensadores. São Paulo: Abril Cultural, 1978.

BAUMAN, Zygmunt. Life in fragments: Essays in postmodern morality. 1995.

BENJAMIN, Walter. Charles Baudelaire Um Lírico no Auge do Capitalismo. Tradução José Carlos Martins Barbosa, Hemerson Alves Baptista. 1 ed. São Paulo: Brasiliense, 1989. - (Obras Escolhidas; v.3)

BERMAN, Marshall. Tudo que é sólido desmancha no ar. Companhia das Letras, 1990.

CAETANO, Kati. Impregnações tecnoestéticas na vida cotidiana: inconsciente óptico, filosofia da caixa preta, artealização e "everyware". Revista Em Questão. Porto Alegre: 
Revista Tecnologia e Sociedade, Curitiba, v. 11, n. 23, 2015

ISSN (versão online): 1984-3526

ISSN (versão impressa): 1809-0044

Faculdade de Biblioteconomia e Comunicação da UFRGS, vol. 18, n. 1, 2012, p. 245 - 262. Disponível em: <http://seer.ufrgs.br/EmQuestao>.

CAETANO, Kati; FISCHER, Sandra. Controle, fratura, profanação, escapatória: a poética do olhar em Gigante. Control, fracture, profanity, escape: the poetics of looking in Gigante. XXIIII Encontro Anual da Compôs, Universidade Federal do Pará, 2014.

DIDI-HUBERMAN. O que vemos, o que nos olha. São Paulo: Editora 34, 2010.

GREIMAS, Algirdas - Julien. Da imperfeição. São Paulo: Hacker Editores, 2002.

HAROCHE, Claudine. A condição sensível: formas e maneiras de sentir no Ocidente. Trad. Jacy Alves de Seixas e Vera Avellar Ribeiro. Rio de Janeiro: Contra Capa, 2008.

HEIDEGGER, Martin. Conferências e Escritos Filosóficos. Tradução e notas Ernildo Stein. São Paulo: Abril Cultural, 1979. (Os Pensadores, Heidegger)

LEMOS, André. Ciber-flânerie. Comunicação na cibercultura. São Leopoldo (RS): Editora Unisinos, 2001.

LEMOS, André. Cidade-ciborgue: a cidade na cibercultura. Galáxia, v. 4, n. 8, 2007.

MACHADO, Arlindo. A Ilusão Especular - Introdução à fotografia. São Paulo: Brasiliense, 1984.

RIBEIRO, Clarissa. Do flâneur ao ciborg-teorias filosóficas do espaço. Entre e através_Complexidade e processos de design em Arquitetura, USP, 2004.

VIRILIO, Paul. O Espaço crítico. Tradução Paulo Roberto Pires. 1. ed. Rio de Janeiro: Editora 34, 1993.

\section{FILMOGRAFIA:}

MEDIANERAS. Direção de Gustavo Taretto. Argentina: 2011 